Marieke Zwaanswijk

Peter F. M. Verhaak

Jan van der Ende

Jozien M. Bensing

Frank C. Verhulst
Accepted: 7 November 2005 /

Published online: 16 January 2006
M. Zwaanswijk ( $\square)$ P. P. M. Verhaak J. M. Bensing

NIVEL, Netherlands Institute for Health Services Research

P.O. Box 1568

3500 BN Utrecht, The Netherlands

E-Mail: M.Zwaanswijk@nivel.nl

M. Zwaanswijk · J. van der Ende

F. C. Verhulst

Dept. of Child and Adolescent Psychiatry

Rotterdam, The Netherlands

\title{
Change in children's emotional and behavioural problems over a one-year period
}

\section{Associations with parental problem recognition and service use}

Abstract Although children with emotional or behavioural problems are at increased risk of future problems, knowledge of factors associated with persistence and change in child problems, once these problems exist, is limited. Using repeated measures analyses of variance, the present study investigated the association of parental problem recognition, professional and informal service use, and sociodemographic factors with change in child problems over a one-year period, in a sample of 360 children and adolescents with emotional and behavioural problems. Higher overall problem levels were found in children (aged 411 years at baseline) versus adolescents (aged 12-17 years), in boys, and in children with less educated parents, which indicates the need to address preventive actions at these groups. Although rates of service use were low, children who had been in contact with general practitioners or mental health services had higher overall problem levels, suggesting that children who need it most end up receiving professional care. Although child emotional and behavioural problems decreased significantly over time, this change was not associated with utilisation of professional or informal services. Our findings imply the need for methodologically sound research into the effectiveness of professional and informal services for child emotional and behavioural problems.

Key words child and adolescent psychopathology - problem recognition - service use longitudinal change

\section{Introduction}

Children with emotional or behavioural problems are at an increased risk for persistence of problems in following years [8]. Little is known, however, about the factors associated with persistence and change in child problems once they manifest themselves. In a sample of children referred to a psychiatric clinic, improvement in child problems was positively associated with male gender, child age, and length of follow-up interval. The strongest predicting factor for later psychopathology was previous child psychopathology, and few other child, family, and treatmentrelated factors had additional predictive value [6].

Although Heijmens Visser et al. investigated the association of service use with later child psychopathology, their focus was restricted to mental health service use only. Since only a minority of children with emotional or behavioural problems receive mental health care $[5,7,9,12]$, and parents of problematic children tend to seek help from a variety of 
sources besides mental health care (e.g. informal care, primary care), it is interesting to investigate the association of these various types of care with change in child problems over time. The present study aims to provide a reflection of this multi-faceted nature of service use for child emotional and behavioural problems by investigating the extent to which utilisation of professional (general practitioner, mental health care) and informal services (teacher, friends or relatives) is associated with change in children's problems over a one-year period. Parents' acknowledgement of the presence of emotional or behavioural problems in their child (problem recognition) and sociodemographic factors (child gender, age group, parental education level) are also investigated as possible correlates of change in children's problems.

\section{Methods}

The sample used in this article is part of a larger study on help-seeking for child emotional and behavioural problems. For a more detailed description of the methodology of this study, see Zwaanswijk et al. [13, 14]. Data were obtained from the Second Dutch National Survey of General Practice, in which 2431 parents of children (aged 4-17), who were randomly chosen from a representative sample of Dutch general practice patients, participated in an extensive health interview survey [11]. The patients listed in the participating general practices were comparable to the general Dutch population with respect to age, gender, and type of health insurance [11]. As part of the health interview, children were screened for the presence of emotional or behavioural problems by means of the Child Behavior Checklist (CBCL) [1], Teacher's Report Form (TRF) [2], and Youth SelfReport (YSR) [3]. Parents of children scoring in the deviant range of the CBCL, TRF, or YSR Total Problems scales based on the cut-off points suggested by Achenbach [1-3], were asked to participate in an interview on help-seeking (T1). Parents of 360 of the originally 553 selected children participated (65.1\%). Children of respondents and non-respondents did not differ significantly in age, gender, CBCL and TRF Total Problems scores, but participating parents were more highly educated (Mann-Whitney $U$-test; $P<$ 0.01 ) and their children had lower YSR Total Problems scores ( $T$-test; $P<0.05$ ).

One year after the first interview, 317 respondents (response: $88.1 \%$ ) again filled in the CBCL, YSR, and a questionnaire on help-seeking (T2). No significant differences between respondents and non-respondents were found for child gender, child age, parents' education level, CBCL Total Problems score, and contact with professional or informal services on $\mathrm{T} 1$.
At both time points, parents were asked whether or not they had used help for child emotional or behavioural problems from general practitioners (GPs), mental health care, teachers, and friends or relatives during the year preceding assessment. Parental problem recognition was assessed at $\mathrm{T} 1$ by asking whether the child had an emotional or behavioural problem.

To investigate factors associated with change in the level of problem scores, repeated measures analyses of variance were used, with the variables listed in Table 1 as between-subjects factors. Based on child age on $\mathrm{T} 1$, the sample was dichotomised into children (aged 4-11 years) and adolescents (aged 12-17 years). Because of the effect of parental education level on T1 participation, we controlled for this variable in the analyses. Analyses were restricted to parent reports of child problems (CBCL Total Problems), because TRF data were not obtained at $\mathrm{T} 2$, and the number of respondents for whom YSR data were available for both time points was limited $(N=87)$, because of the restricted age range in which the YSR can be administered.

After testing the strength of the association of each variable with change in problem scores independently, variables with significant effects were entered into a multiple analysis to determine their unique contribution over and above the effects of all other variables. When a significant effect was found for parental education level, dummy variables were subsequently included in the model to test whether the patterns of change for children from highly and moderately educated parents differed significantly from the pattern for children from parents with low education level.

\section{Results}

Since our sample was screened for the presence of emotional or behavioural problems, the overall mean CBCL Total Problems scores at T1 (36.9; s.d. 18.3) and at T2 (28.3; s.d. 20.9) were above the means of a Dutch normative sample [10]. However, because screening was based on deviant Total Problems scores on at least one of three separate measures (CBCL, TRF, and YSR), not all, but 244 children (68\%) in our sample had deviant CBCL Total Problems scores at T1.

Overall, CBCL Total Problems scores decreased significantly over a one-year period (T-test; $P<$ 0.01 ). In $34.3 \%$ of our sample, scores changed from deviant to normal level during the assessment period, whereas in $2.2 \%$ scores deteriorated from the normal to the deviant range. Comparable percentages of children remained in either the deviant $(33.3 \%)$ or the normal range $(30.2 \%)$. 
Table 1 Descriptives of factors included in the present study, and their within-subjects and between-subjects effects on the change in the CBCL Total Problems scores

\begin{tabular}{|c|c|c|c|c|c|c|c|c|}
\hline & \multicolumn{8}{|c|}{ Total Problems } \\
\hline & \multirow[b]{2}{*}{ N } & \multirow[b]{2}{*}{$\%$} & \multicolumn{2}{|l|}{ Means } & \multicolumn{2}{|c|}{ Within } & \multicolumn{2}{|c|}{ Between } \\
\hline & & & $\mathrm{T} 1$ & $\mathrm{~T} 2$ & $F$ & $P$ & $F$ & $P$ \\
\hline Child gender & 360 & $\begin{array}{l}54.4 \% \text { boys } \\
45.6 \% \text { girls }\end{array}$ & $\begin{array}{l}39.35 \\
34.02\end{array}$ & $\begin{array}{l}31.33 \\
24.62\end{array}$ & 0.38 & 0.54 & 4.08 & 0.04 \\
\hline Child age group at $\mathrm{T} 1$ & 360 & $\begin{array}{l}68.3 \% \text { child } \\
31.7 \% \text { adolescent }\end{array}$ & $\begin{array}{l}38.76 \\
32.96\end{array}$ & $\begin{array}{l}29.97 \\
24.26\end{array}$ & 0.01 & 0.93 & 7.98 & 0.01 \\
\hline Parental education level & 357 & $\begin{array}{l}13.4 \% \text { low } \\
50.1 \% \text { moderate } \\
36.5 \% \text { high }\end{array}$ & $\begin{array}{l}39.81 \\
38.35 \\
34.08\end{array}$ & $\begin{array}{l}33.00 \\
30.65 \\
23.45\end{array}$ & 0.82 & 0.44 & 5.14 & 0.01 \\
\hline Parental problem recognition & 354 & $\begin{array}{l}42.9 \% \text { yes } \\
57.1 \% \text { no }\end{array}$ & $\begin{array}{l}43.39 \\
32.23\end{array}$ & $\begin{array}{l}37.04 \\
21.44\end{array}$ & 0.03 & 0.87 & 2.21 & 0.14 \\
\hline Service use & & & & & & & & \\
\hline General practitioner & 311 & $\begin{array}{l}17.4 \% \text { yes } \\
82.6 \% \text { no }\end{array}$ & $\begin{array}{l}50.24 \\
34.36\end{array}$ & $\begin{array}{l}44.72 \\
24.98\end{array}$ & 0.10 & 0.76 & 7.27 & 0.01 \\
\hline Mental health services & 311 & $\begin{array}{l}18.0 \% \text { yes } \\
82.0 \% \text { no }\end{array}$ & $\begin{array}{l}47.09 \\
34.89\end{array}$ & $\begin{array}{l}41.95 \\
25.18\end{array}$ & 1.53 & 0.22 & 4.11 & 0.04 \\
\hline Teacher & 311 & $\begin{array}{l}36.0 \% \text { yes } \\
64.0 \% \text { no }\end{array}$ & $\begin{array}{l}44.20 \\
33.14\end{array}$ & $\begin{array}{l}37.68 \\
23.08\end{array}$ & 0.14 & 0.71 & 0.10 & 0.75 \\
\hline Friends or relatives & 311 & $\begin{array}{l}34.4 \% \text { yes } \\
65.6 \% \text { no }\end{array}$ & $\begin{array}{l}45.45 \\
32.75\end{array}$ & $\begin{array}{l}38.82 \\
22.83\end{array}$ & 0.16 & 0.69 & 2.82 & 0.09 \\
\hline
\end{tabular}

Note: Service use was assessed at $\mathrm{T} 1$ and/or T2

When asked directly whether their child had an emotional or behavioural problem (parental problem recognition), $42.9 \%$ of parents confirmed the presence of such problems. This percentage was somewhat higher $(48.8 \%)$ for parents whose children scored in the deviant range of the CBCL Total Problems scale at T1. Children with deviant CBCL Total Problems scores combined with parental problem recognition scored significantly higher on all CBCL syndrome scales (except for Somatic Complaints; $T$-tests; $P<$ $0.05)$ than deviant scoring children without parental problem recognition.

Frequencies of professional and informal service use for the total sample are presented in Table 1. Children who had used services had significantly more problems at baseline than those who had not used the same type of services, both when CBCL Total Problems were assessed continuously ( $T$-tests; $P<$ $0.01)$ and when they were dichotomised into deviant versus normal range ( $\chi^{2}$-tests; $\left.P<0.05\right)$. Within the group of children scoring in the deviant range of the T1 CBCL Total Problems scale, service utilisation was significantly more frequent among those with additional parental problem recognition $\left(\chi^{2}\right.$-tests; $P<$ 0.01; data not shown in Table 1). Users and non-users showed significant reductions of Total Problems scores over time ( $T$-tests; $P<0.05$ ). These effects were found for professional as well as informal services.

When assessed independently, all factors had significant within-subjects or between-subjects effects on the change in the CBCL Total Problems scores, and were therefore included in the multiple repeated measures analyses of variance. Results of the latter analysis are listed in Table 1.

After controlling for the presence of other variables, none of the variables included in the analysis had significant within-subjects effects on the change in CBCL Total Problems scores. Child gender, child age group at baseline, parental education level, contact with GP, and mental health service use had significant between-subjects effects. Higher Total Problems scores were therefore found for children (aged 4-11 years at baseline) versus adolescents (aged 12-17 years), for boys, and for children who had used help from GPs or mental health services at T1 and/or T2. Children from parents with low education level had significantly higher CBCL Total Problems scores than children from highly educated parents.

\section{Discussion}

The present study was aimed at investigating the extent to which parents' recognition of child emotional and behavioural problems, professional and informal service use for these problems, and sociodemographic factors were associated with change in child problems over a one-year period.

In general, emotional and behavioural problems decreased significantly over the course of one year, 
both in the sample as a whole and in children who had used professional or informal services. However, the mean CBCL Total Problems scores for the total sample and for service users remained above the normative mean after one year, indicating the problematic nature of the sample.

The rates of service use were low. Even in a sample selected for having emotional and behavioural problems, merely $18 \%$ of children had used professional services, and $35 \%$ had used informal services. However, the finding that children who had used services had significantly more emotional and behavioural problems at baseline than children who had not used services [cf. 4,6] suggests that, in part, children who need it the most end up receiving care. This was confirmed by the finding that, after controlling for other variables, children who had been in contact with GPs or mental health care had significantly higher problem scores over the course of one year.

Whereas service use was significantly more frequent for children with emotional or behavioural problems in the deviant range, parents' acknowledgement of the presence of such problems had an additional influence on the frequency of service use within the deviant scoring group. Considering the fact that less than half of the parents who reported child problems in the deviant range also acknowledged the presence of these problems when asked directly, parents' non-recognition of child problems could constitute a first reason for parents not seeking help. On the other hand, children with deviant CBCL Total Problems scores who were also recognised as problematic by their parents had more serious problems than children without parental problem recognition. The concept of parental problem recognition may therefore distinguish between children with emotional or behavioural problems who are able to function adequately, and those requiring special attention.

The elevated problem scores in boys, younger children and children from less educated families indicate the need to address preventive actions at those groups. This is even more salient since children from lower-educated families were underrepresented in this study and problem levels in those children may therefore have been underestimated. Moreover, the previous finding of older children showing more improvement in emotional and behavioural problems over a six-year interval [6] underscores the need to focus prevention at young children.

An intriguing question is whether children with emotional or behavioural problems need some sort of care to ensure them to develop towards less problematic behaviour, or whether their problems would anyhow reduce over time. The absence of an association between any of the four types of service use and the change in child problems found in the present study might be interpreted as evidence for the latter assumption. However, we believe that this finding does not automatically imply the ineffectiveness of professional and informal services in reducing child emotional and behavioural problems. The limited time span of the study and the use of screening questionnaires instead of interviews to measure child problems may have prevented detection of any associations between service use and change in child problems. Also, service use may have affected aspects of the child's development not covered by our outcome measure. More importantly, our study contained limitations that are typical for naturalistic designs, such as the impossibility of random assignment to conditions, inclusion of a broad range of treatments, and the presence of many possibly confounding factors, which restrict the possibility of drawing firm conclusions about the effectiveness of services in reducing child symptoms. The chronicity of child psychopathology and the limited use of empirically validated treatments may, on the other hand, indeed prevent services from being effective. What our findings do imply, therefore, is the need for methodologically sound research into the effectiveness of professional and informal services for child emotional and behavioural problems, with large samples, multiple data waves, and assessment of outcomes on multiple domains [4].

Acknowledgement This study was financially supported by grant number 2100.0064 from the Netherlands Organisation for Health Research and Development.

\section{References}

1. Achenbach TM (1991) Manual for the Child Behavior Checklist/4-18 and 1991 Profiles. University of Vermont Department of Psychiatry, Burlington
2. Achenbach TM (1991) Manual for the Teacher's Report Form and 1991 Profiles. University of Vermont Department of Psychiatry, Burlington
3. Achenbach TM (1991) Manual for the Youth Self-Report and 1991 Profiles. University of Vermont Department of Psychiatry, Burlington 
4. Angold A, Costello EJ, Burns BJ, Erkanli A, Farmer EMZ (2000) Effectiveness of nonresidential specialty mental health services for children and adolescents in the "Real World". J Am Acad Child Adolesc Psychiatry 39:154-160

5. Burns BJ, Costello EJ, Angold A, Tweed D, Stangl D, Farmer EM, Erkanli A (1995) Children's mental health service use across service sectors. Health Aff 14:147-159

6. Heijmens Visser J, Van der Ende J, Koot HM, Verhulst FC (2003) Predicting change in psychopathology in youth referred to mental health services in childhood or adolescence. J Child Psychol Psychiatry 44:509-519

7. Leaf PJ, Alegria M, Cohen P, Goodman SH, Horwitz SM, Hoven CW, Narrow WE, Vaden-Kiernan M, Regier DA (1996) Mental health service use in the community and schools: results from the four-community MECA study. J Am Acad Child Adolesc Psychiatry 35:889897
8. Verhulst FC, Van der Ende J (1992) Sixyear developmental course of internalizing and externalizing problem behaviors. J Am Acad Child Adolesc Psychiatry 31:924-931

9. Verhulst FC, Van der Ende J (1997) Factors associated with child mental health service use in the community. J Am Acad Child Adolesc Psychiatry 36:901-909

10. Verhulst FC, Van der Ende J, Koot HM (1996) Handleiding voor de CBCL/4-18 [Manual for the CBCL/4-18]. Afdeling Kinder- en Jeugdpsychiatrie. Sophia Kinderziekenhuis/Academisch Ziekenhuis Rotterdam/Erasmus Universiteit, Rotterdam

11. Westert GP, Schellevis FG, De Bakker DH, Groenewegen PP, Bensing JM, Van der Zee J (2005) Monitoring health inequalities through general practice: the second Dutch National Survey of General Practice. Eur J Public Health 15:59-65
12. Zwaanswijk M, Van der Ende J, Verhaak PFM, Bensing JM, Verhulst FC (2003) Factors associated with adolescent mental health service need and utilization. J Am Acad Child Adolesc Psychiatry 42:692-700

13. Zwaanswijk M, Van der Ende J, Verhaak PFM, Bensing JM, Verhulst FC (2005) Help-seeking for child psychopathology: pathways to informal and professional services in the Netherlands. J Am Acad Child Adolesc Psychiatry 44:1292-1300

14. Zwaanswijk M, Van der Ende J, Verhaak PFM, Bensing JM, Verhulst FC (submitted) Stages and actors involved in the process leading to adolescent mental health service use. 